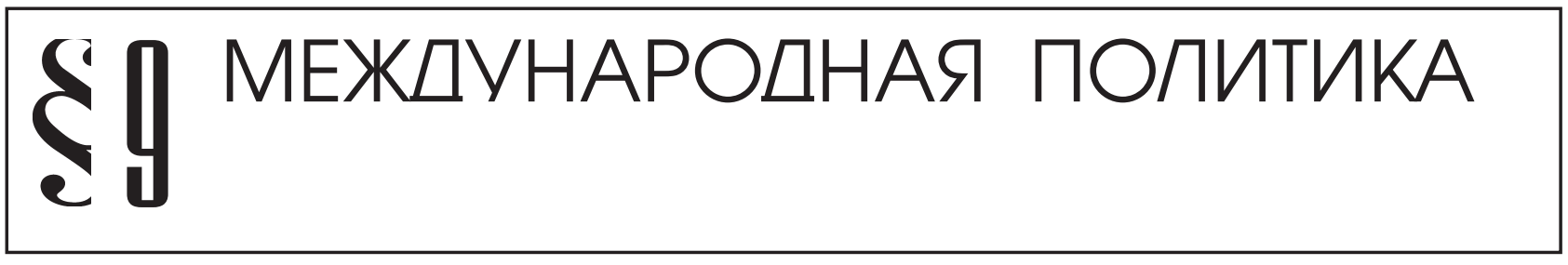

Мальцев C.C.

\title{
МИРОВОЙ ПОЛИТИЧЕСКИЙ ПРОЦЕСС В КОНТЕКСТЕ РАЗВИТИЯ ГЛОБАЛЬНЫХ НАВИГАЦИОННЫХ СПУТНИКОВЫХ СИСТЕМ (ГНСС)
}

Аннотация: Зародивиись как национальные, Глобальные навигационные спутниковые системь (ГНСС) давно предоставляют навигачионные услуги международным потребителям, глубоко проникнув во все ключевые отрасли международной экономики. При этом, критическая зависимость социально-экономической инфраструктуры развитых государств от их стабильного и непрерывного функиионирования, подталкивает наиболее сильных международных игроков к разработке альтернативных американской системе GPS, подконтрольной Министерству обороны США, глобальных систем (EC - проект Galileo, КНР - Coтраss, Россия - ГЛОНАСC) либо к необходимости сотрудничества в этой сфере с США в рамках соответствующих двусторонних соглашений. В данной статье раскрывается взаимосвязь обеспечения национальной и международной безопасности с функиионированием ГНСС как доминанты современного мирового политического процесса. Также проводится и анализ структуры основных МПП в контексте международного развития таких систем. Методологическую основу исследования составляет парадигма политического неореализма с точки зрения обеспечения национальной безопасности государства и производной международной деятельности для ее обеспечения посредством эксплуатации/использования ГНСС. Говоря об основных выводах исследования и структуре акторов мирового политического процесса в контексте развития ГНСС, следует признать, что наибольшая активность наблюдается не на глобальном и региональном уровнях, а на суверенном уровне. Несмотря на то, что ГНСС сегодня отнюдь не функиионируют в международно-правовом вакууме, - их деятельность находится в поле зрения глобальных акторов мирового политического процесса, прежде всего ООН и ее официальных учреждений и организаций (ICAO, IMO, ITU и т.д.). Тем не менее, сохранение активной роли институтов ООН в этом процессе является достижением периода «холодной»войны и при условии сохранения текущих тенденщий в развитии мировой системы международных отношений, будет иметь тендениию к снижению.

Review: Even though they were first created as the national phenomenon, Global Navigation Satellite Systems (GLONASS) have been providing navigation services to international consumers for quite a long time. GLONASS became part of all the key branches of international economy. Noteworthy that the critical dependence of social and economic infrastructure of developed countries on their stable and sustainable functioning and development makes the largest international actors either to develop alternative American GPS systems controlled by the United States Department of Defense and global systems (Galileo in the EU, Compass in the PRC, GLONASS in Russia) or seek for cooperation with the USA. The author of the present article describes the relation between national and international security and GLONASS as the dominant of the modern global political process. The author also analyzes the structure of the main World Food Programs in terms of the global development of these systems. Methodological basis of research is the paradigm of political neo realism from the point of view of national security and associated international activity aimed at providing national security through using/implementing GLONASS. Speaking of the main conclusions made by the author and the structure of actors of the global political process as the part of development of GLONASS, it is necessary to admit that the greatest activity is viewed at the sovereign level but not global or regional levels. Despite the fact that today GLONASS does not function in the international law environment, their activity is still within the sight of the actors of the global political process, first of all, United Nations and its official departments and organizations (ICAO, IMO, ITU and etc.). Nevertheless, taking into account current tendencies in the development of global international relations, active role of the UN institution may decrease. 
Ключевые слова: ГНСС, мировой политический процесс, международная безопасность, ООН, международные отношения, ГЛОНАСС, национальные интересы, глобализация, GPS, международное космическое право.

Keywords: GLONAS, global political process, international security, United Nations, international relations, Global Navigation Satellite System, national interests, globalization, GPS, international space law.

$\mathrm{M}$ ировой политический процесс сегодня характеризуется переходом от однополярного к многополюсному миру при ослаблении лидирующих позиций США, при этом, доминантой современного международного политического процесса остается проблема укрепления международной безопасности. Это связано как с противодействием процессу глобализации и связанной с ним экспансии в экономической, информационной, культурной и военно-политической сферах, так и с противоречивостью характера взаимодействий между основными центрами силы. Многообразие форм экспансии и взаимозависимость ключевых игроков приводит к тому, что даже самые сильные государства становятся объектами экспансии. Ярким примером служит экономическая зависимость США и ЕС от поставок китайских товаров и ближневосточных углеводородов. Такие характеристики мирового политического процесса с одной стороны, приводят к тому, что международные политические отношения сегодня тесно переплетены с международными экономическими отношениями и обеспечение национальной безопасности зачастую становится тождественно обеспечению безопасности экономической. С другой стороны, в условиях глобализации становится практически невозможным отделение национальной безопасности от обеспечения международной безопасности ${ }^{1}$.

При этом, в современных условиях, проблема обеспечения глобальной безопасности уже не тождественна режиму нераспространения ядерного оружия, - главного сдерживающего периода фактора «холодной» войны. Компьютеризация и информационная революция стерли границы между войной и миром, в военном деле наступает новый этап развития с повсеместным использованием высокоточного оружия, требующего получения информации из космоса и высокоточных координат. Это коренным образом меняет общее соотношение

\footnotetext{
${ }^{1}$ Косолапов Н.А. Безопасность международная, национальная, глобальная: взаимодополняемость или противоречивость // Мировая экономика и международные отношения. - 2006. - № 9. - С. 3-13.
}

сил, в частности - влияет на возможность массового превентивного удара высокоточным оружием в одностороннем порядке ${ }^{2}$. Кроме того, внедрение высоких технологий существенно изменило характер и возможности обычных вооружений, системы разведки и управления войсками, расширило возможности ведения войны на расстоянии, обеспечения «малой заметности» военной техники и т.д. ${ }^{3}$ Поэтому ключевая роль в обеспечении безопасности в столь ее широкой трактовке, отводится глобальным навигационным спутниковым системам (ГНСС) как квинтэссенции развития военной мысли и ключевому критерию оценки научно-технического потенциала ведущих государств.

Спутниковая навигация проникла сегодня во все важные отрасли глобальной экономики. Без нее уже невозможно представить развитие современного сельского хозяйства, строительства, горнодобывающей промышленности, геодезии и картографии, аварийно-спасательных служб, транспортной логистики, персональной навигации и т.д. Кроме того, услуги точного времени, предоставляемые спутниками ГНСС, имеют решающее значение для функционирования системы сотовой связи (более эффективное переиспользование ограниченного частотного ресурса множеством базовых станций), энергетических сетей smart-network (эффективность передачи и распределения электроэнергии), мировых финансовых сетей (контроль транзакций глобальных сетей банкоматов, синхронизация распределенных банковских компьютерных сетей и т.д.). Поэтому некорректная работа ГНСС, равно как и внезапное прекращение обслуживания вследствие естественных причин либо целенаправленного воздействия, могут привести к серьезным последствиям и ущербу. К примеру, в ЕС только по

\footnotetext{
2 Фененко A. Конкуренция в космосе и международная безопасность // Международные процессы. - 2008. - №3. - Режим доступа: http://www.intertrends.ru/eighteenth/004.htm (дата обращения 25.05.2011).

${ }^{3}$ Крылов А. Военные спутниковые системы связи в начале XXI века // Журнал «Вестник ГЛОНАСС». - 2012. - №1. C.21-26.
} 


\section{Политика и общество 3 (111) • 2014}

состоянию на 2002 г. прогнозировали ежедневный экономический ущерб от прекращения работы системы GPS до €0,5 млрд.

Критическая зависимость социально-экономической инфраструктуры развитых государств от ГНСС, и прежде всего, от американской GPS, равно как и изначальные военные возможности ее использования, подталкивает наиболее сильных международных игроков к разработке альтернативных глобальных (ЕC - проект Galileo, КНР - Compass, Россия - ГЛОНАСС) и региональных систем (GAGAN/IRNSS для Индии и MSAS/QZSS для Японии) либо к необходимости сотрудничества в этой сфере с США в рамках соответствующих двусторонних соглашений. Значение ГНСС сегодня таково, что положение дел практически ничем не отличается от ситуации полувековой давности, когда ключевым элементом мировой системы сдержек и противовесов выступало наличие ракетно-ядерного потенциала. Однако, если в период «Холодной войны» система международных отношений была относительно стабильна, основываясь на двух полюсах силы, взаимный интерес которых к сдерживанию противоположного лагеря, привел к разработке международно-правовой базы по сокращению ракетно-ядерного потенциала и ограничению его использования, то самоустранение Восточного блока и укрепление доминирующего положения оставшегося центра силы в 1990-е гг. не позволяют сегодня создать международную договорную базу по ГНСС, учитывающую интересы, не тождественные национальным интересам США 5 . Это связано с тем, что само возникновение новой подотрасли международного космического права - спутниковой навигации - пришлось на третий этап его развития (1980-1996 гг.), когда из-за противоречий между государствами выработать обязывающие международные соглашения по ГНСС не удалось ${ }^{6}$.

В этой связи было бы интересно сопоставить деятельность акторов современного мирового политического процесса с развитием международно-правовой базы для функционирования ГНСС. Стоит отметить, что при всей сложности и много-

${ }^{4}$ J.Vielhaber and D.Sattler. Why Europe wants Galileo? // Journal Internationale Politik. - Winter 2002. - Vol.3. - P. 58-6

${ }_{5}^{5}$ Международное космическое право/ Отв. редакторы проф. Жуков Г. П. и проф. Колосов Ю. М. - «Международные отношения». - М.,1999. - 408 с.

${ }^{6}$ Международное право: учебник/ отв. ред. А.Н. Вылегжанин. - М.: Высшее образование, Юрайт-Издат, 2009. - С. 878-881 гранности совокупности базовых (центральных) и периферийных, транснациональных, региональных, национальных и локальных, цивилизационных и этнополитических политических процессов, структурно ключевых акторов мирового политического процесса можно разделить на глобальных, региональных и локальных/национальных. При этом, в контексте международного развития ГНСС, наибольшая активность наблюдается не на глобальном и региональном уровнях, а на уровне суверенных государств. Двусторонние межгосударственные соглашения по развитию ГНСС характерны не только для США и Российской Федерации, уже обладающих полноценными системами, но и для неофитов в лице КНР, Европейского Союза, Индии, Японии. В то же время, несмотря на отсутствие международных договоров, ГНСС сегодня отнюдь не функционируют в международно-правовом вакууме. Их деятельность находится в поле зрения глобальных акторов мирового политического процесса, прежде всего ООН и ее официальных учреждений и организаций (ICAO, IMO, ITU). Однако стоит признать, что первостепенную роль в выработке политико-правовых основ функционирования ГНСС и предоставления их услуг международным потребителям, играют все же сами государства-разработчицы. Сохранение активной роли институтов ООН в этом процессе является достижением периода «холодной» войны и при условии сохранения текущих тенденций в развитии мировой системы международных отношений, будет иметь тенденцию к снижению.

Вместе с тем, нельзя полностью утверждать, что на уровне региональных акторов международного политического процесса совсем ничего не происходит. Это не так, - такая деятельность связана с активностью субрегиональных международных организаций по стандартизации. К таким акторам в контексте ГНСС можно отнести различные международные неправительственные организации по стандартизации, подконтрольные США и ЕC: RTCM, RTCA, EASA, EUROCAE, IEC и другие. На основе их рекомендаций вырабатываются уже международные стандарты ключевых для ГНСС отраслевых организаций ООН, - Международной морской организации IMO, Международной организации гражданской авиации ICAO и Международного союза электросвязи ITU. Таким образом, благодаря контролю ключевых акторов регионального и субрегионального уровня, участвующих в стандартизации 
оборудования ГНСС, США и ЕС активно влияют на акторов глобального уровня. Россия же в настоящее время не играет заметной роли в этой сфере, ограничиваясь переводом на русский язык европейских стандартов, соответствующих, в свою очередь, американским. Без смены парадигмы развития и начала активной работы в сфере международной стандартизации, продвижение ГЛОНАСС на мировой потребительский рынок будет невозможным.

\section{Библиография:}

1. Международное космическое право/ Отв. редакторы проф. Жуков Г. П. и проф. Колосов Ю. М. «Международные отношения». - М., 1999. - 408 с.

2. Международное право: учебник/ отв. ред. А.Н. Вылегжанин. - М.: Высшее образование, Юрайт-Издат, 2009. - С. 878-881

3. Косолапов Н.А. Безопасность международная, национальная, глобальная: взаимодополняемость или противоречивость // Мировая экономика и международные отношения. - 2006. - № 9. - С. 3-13.

4. Крылов А. Военные спутниковые системы связи в начале XXI века // Журнал «Вестник ГЛОНАСС». - 2012.-№1. - С.21-26.

5. Фененко А. Конкуренция в космосе и международная безопасность // Международные процессы. - 2008. - №3. - Режим доступа: http://www. intertrends.ru/eighteenth/004.htm (дата обращения 25.05.2011).

6. J.Vielhaber and D.Sattler. Why Europe wants Galileo? // Journal Internationale Politik. - Winter 2002.

- Vol.3. - P. 58-6

7. Цыганков П.А. Негосударственные участники мировой политики: взаимодействие с государствами и межправительственными организациями // Международные отношения. - 2013. - 3. C. 312-317. DOI: 10.7256/2305-560X.2013.3.8977.

8. Калюжная Д.Е. Современные акторы мировой политики и переход к устойчивому развитию // NB: Проблемы общества и политики. - 2013. 5. - C. 45-87. DOI: 10.7256/2306-0158.2013.5.664. URL: http://www.e-notabene.ru/pr/article_664.html

9. Арапов А.В. Глобальное управление: концепции и тенденции // Международные отношения. - 2014. - 1. - C. 81-87. DOI: 10.7256/2305560X.2014.1.9687.
10. Савинов А.Н., Меркушев О.Ю.. Защита биометрических подсистем управления доступом. // Программные системы и вычислительные методы.-2013. - № 4. - С. 335-343. DOI: .10.7256/23056061.2013.4.11092.

11. Кожевников Е.А.. Перспективные системы и средства радиоэлектронной борьбы противника для противодействия системам спутниковой связи. // Национальная безопасность / NOTA BENE. - 2014. - № 1. - C. 104-107. DOI: .10.7256/20738560.2014.1.5145.

12. Арапов А.В.. Глобальное управление: концепции и тенденции . // Международные отношения. - 2014. - № 1. - С. 81-87. DOI: .10.7256/2305560X.2014.1.968

\section{References (transliteration):}

1. Kosolapov N.A. Bezopasnost' mezhdunarodnaya, natsional'naya, global'naya: vzaimodopolnyaemost' ili protivorechivost' // Mirovaya ekonomika i mezhdunarodnye otnosheniya. - 2006. - № 9. - C. 3-13.

2. Krylov A. Voennye sputnikovye sistemy svyazi v nachale XXI veka // Zhurnal «Vestnik GLONASS». - 2012.-№1. - S.21-26.

3. Fenenko A. Konkurentsiya $\mathrm{v}$ kosmose i mezhdunarodnaya bezopasnost' // Mezhdunarodnye protsessy. - 2008. - №3. - Rezhim dostupa: http://www.intertrends.ru/eighteenth/004.htm (data obrashcheniya 25.05.2011).

4. J.Vielhaber and D.Sattler. Why Europe wants Galileo? // Journal Internationale Politik. - Winter 2002. - Vol.3. - P. 58-6

5. Tsygankov P.A. Negosudarstvennye uchastniki mirovoi politiki: vzaimodeistvie s gosudarstvami i mezhpravitel'stvennymi organizatsiyami // Mezhdunarodnye otnosheniya. - 2013. - 3. - C. 312-317. DOI: 10.7256/2305-560X.2013.3.8977.

6. Kalyuzhnaya D.E. Sovremennye aktory mirovoi politiki i perekhod k ustoichivomu razvitiyu // NB: Problemy obshchestva i politiki. - 2013. - 5. - C. 45-87. DOI: 10.7256/2306-0158.2013.5.664. URL: http:// www.e-notabene.ru/pr/article_664.html

7. Arapov A.V. Global'noe upravlenie: kontseptsii i tendentsii // Mezhdunarodnye otnosheniya. - 2014. - 1 . - C. 81-87. DOI: 10.7256/2305-560X.2014.1.9687.

8. Savinov A.N., Merkushev O.Yu.. Zashchita biometricheskikh podsistem upravleniya dostupom. 
DOI: $10.7256 / 1812-8696.2014 .3 .11531$

При цитировании этой статьи сноска на dоі обязательна

\section{Политика и общество 3 (111) • 2014}

// Programmnye sistemy i vychislitel'nye metody. - 2013. - № 4. - C. 335-343. DOI: .10.7256/23056061.2013.4.11092.

9. Kozhevnikov E.A.. Perspektivnye sistemy i sredstva radio-elektronnoi bor'by protivnika dlya protivodeistviya sistemam sputnikovoi svyazi. // Natsional'naya bezopasnost' / nota bene. - 2014. - № 1. - C. 104107. DOI: .10.7256/2073-8560.2014.1.5145.

10. Arapov A.V.. Global'noe upravlenie: kontseptsii i tendentsii . // Mezhdunarodnye otnosheniya. - 2014. - № 1. - C. 81-87. DOI: .10.7256/2305560X.2014.1.968 